\title{
Can segmental mobility be increased by cervical arthroplasty?
}

\author{
*Hsuan-Kan Chang, MD, 1,2 Chih-Chang Chang, MD,,2 Tsung-Hsi Tu, MD,,2 \\ Jau-Ching Wu, MD, PhD, ${ }^{1,2}$ Wen-Cheng Huang, MD, PhD, ${ }^{1,2}$ Li-Yu Fay, MD, ${ }^{1-3}$ \\ Peng-Yuan Chang, MD, ${ }^{1,2}$ Ching-Lan Wu, MD, ${ }^{2,4}$ and Henrich Cheng, MD, PhD ${ }^{1-3}$
}

${ }^{1}$ Department of Neurosurgery, Neurological Institute, Taipei Veterans General Hospital; ${ }^{2}$ School of Medicine and ${ }^{3}$ Institute of Pharmacology, National Yang-Ming University; and “'Department of Radiology, Taipei Veterans General Hospital, Taipei, Taiwan

OBJECTIVE Many reports have successfully demonstrated that cervical disc arthroplasty (CDA) can preserve range of motion after 1- or 2-level discectomy. However, few studies have addressed the extent of changes in segmental mobility after CDA or their clinical correlations.

METHODS Data from consecutive patients who underwent 1-level CDA were retrospectively reviewed. Indications for surgery were medically intractable degenerative disc disease and spondylosis. Clinical outcomes, including visual analog scale (VAS)-measured neck and arm pain, Neck Disability Index (NDI), and Japanese Orthopaedic Association (JOA) scores, were analyzed. Radiographic outcomes, including C2-7 Cobb angle, the difference between pre- and postoperative C2-7 Cobb angle ( $\triangle \mathrm{C} 2-7 \mathrm{Cobb}$ angle), sagittal vertical axis (SVA), the difference between pre- and postoperative SVA ( $\triangle S V A)$, segmental range of motion (ROM), and the difference between pre- and postoperative ROM $(\triangle R O M)$, were assessed for their association with clinical outcomes. All patients underwent $C T$ scanning, by which the presence and severity of heterotopic ossification $(\mathrm{HO})$ were determined during the follow-up.

RESULTS A total of 50 patients (mean age $45.6 \pm 9.33$ years) underwent a 1-level CDA (Prestige LP disc) and were followed up for a mean duration of $27.7 \pm 8.76$ months. All clinical outcomes, including VAS, NDI, and JOA scores, improved significantly after surgery. Preoperative and postoperative ROM values were similar (mean $9.5^{\circ}$ vs $9.0^{\circ}, p>0.05$ ) at each indexed level. The mean changes in segmental mobility $(\triangle R O M)$ were $-0.5^{\circ} \pm 6.13^{\circ}$. Patients with increased segmental mobility after surgery $\left(\triangle \mathrm{ROM}>0^{\circ}\right)$ had a lower incidence of $\mathrm{HO}$ and $\mathrm{HO}$ that was less severe $(p=0.048)$ than those whose $\triangle R O M$ was $<0^{\circ}$. Segmental mobility $(R O M)$ was significantly lower in patients with higher $\mathrm{HO}$ grade $(p=0.012)$, but it did not affect the clinical outcomes. The preoperative and postoperative C2-7 Cobb angles and SVA remained similar. The postoperative C2-7 Cobb angles, SVA, $\triangle \mathrm{C} 2-7 \mathrm{Cobb}$ angles, and $\triangle$ SVA were not correlated to clinical outcomes after CDA.

CONCLUSIONS Segmental mobility (as reflected by the mean ROM) and overall cervical alignment (i.e., mean SVA and C2-7 Cobb angle) had no significant impact on clinical outcomes after 1-level CDA. Patients with increased segmental mobility $\left(\triangle \mathrm{ROM}>0^{\circ}\right)$ had significantly less $\mathrm{HO}$ and similarly improved clinical outcomes than those with decreased segmental mobility $\left(\triangle \mathrm{ROM}<0^{\circ}\right)$.

https://thejns.org/doi/abs/10.3171/2016.10.FOCUS16411

KEY WORDS cervical alignment; Cobb angle; sagittal vertical axis; range of motion; segmental mobility; cervical disc arthroplasty; heterotopic ossification

I $\mathrm{N}$ the past decade cervical disc arthroplasty (CDA) has been considered an effective and safe alternative to anterior cervical discectomy and fusion (ACDF) in selected candidates for management of 1- or 2-level degenerative disc disease (DDD) or spondylosis. ${ }^{10,12,15,18,24,26,35}$ In addition to satisfactory clinical outcomes, successful preservation of segmental mobility after CDA has been demonstrated in several large-scale, prospective, randomized, controlled trials by the United States Food and Drug Administration (FDA). $4,15,23,34,37$ The averaged range of motion (ROM) pre-

ABBREVIATIONS ACDF = anterior cervical discectomy and fusion; CDA = cervical disc arthroplasty; DDD = degenerative disc disease; FDA = Food and Drug Administration; $\mathrm{HO}=$ heterotopic ossification; JOA = Japanese Orthopaedic Association; NDI = Neck Disability Index; ROM = range of motion; VAS = visual analog scale.

SUBMITTED October 1, 2016. ACCEPTED October 14, 2016.

INCLUDE WHEN CITING DOI: 10.3171/2016.10.FOCUS16411.

* Drs J. C. Wu and W. C. Huang contributed equally to this work. 
served at each CDA-treated level was reported to be approximately $7^{\circ}-9^{\circ}$ during flexion and extension. ${ }^{9}, 10,17,24,25,34$ Although the segmental mobility was preserved regardless of the brand of artificial disc that was tested, there are some variations in ROM. However, there are scarce data focusing on the extent of the post-CDA changes in segmental mobility or their clinical correlations.

While the aforementioned Food and Drug Administration (FDA) trials successfully demonstrated preserved segmental mobility (as reflected by mean ROM) after CDA in hundreds of patients, ${ }^{3,4,10,11,17,24,25,28,34}$ these trials did not address individual differences in change of mobility after CDA-in other words, a patient whose segmental mobility might increase (e.g., preoperative flexion and extension ROM of $6^{\circ}$ at C5-6 increasing to $12^{\circ}$ after surgery) or decrease after CDA (e.g., preoperative ROM of $12^{\circ}$ decreasing to $6^{\circ}$ after surgery). These two patients would be summed up as representing preservation of segmental mobility at an average $\mathrm{ROM}$ of $9^{\circ}$. The reported radiographic measurement of mean ROM in the literature would not have picked up the differences between increased and decreased segmental mobility. In theory, increased postoperative ROM (a difference between pre- and postoperative $\left.[\Delta \mathrm{ROM}]>0^{\circ}\right)$ and decreased segmental mobility $(\Delta \mathrm{ROM}$ $<0^{\circ}$ ) could imply substantial differences in CDA. Therefore, the current study focused on the changes in ROM ( $\triangle \mathrm{ROM}$ during flexion and extension) after surgery.

The aim of this present study was to analyze the radiographic outcomes after CDA, particularly the changes in segmental mobility $(\triangle \mathrm{ROM})$ and cervical alignment and establishing correlations between changes and clinical outcomes. The study cohort included consecutively treated patients who underwent a single-level CDA performed using the same kind of device that was approved by the FDA. To the authors' knowledge, this is the first study to specifically address the changes in segmental mobility preoperatively and postoperatively and the influences on the outcomes.

\section{Methods}

\section{Inclusion and Exclusion of Patients}

Data obtained in patients in whom a 1-level subaxial (C3-7) CDA was performed using a Prestige LP disc (Medtronic) were retrospectively reviewed. The study's inclusion criteria were medically intractable cervical radiculopathy, myelopathy, or both, caused by DDD and/or spondylosis at only a single level..$^{17,24,25}$ Preoperative MR images and radiographs were reviewed for all patients for confirmation of diagnosis. Patients also underwent CT scanning for evaluation of extensive bone spur formation, calcified disc, or ossification of the posterior longitudinal ligament. In all cases medical treatment and physical therapy failed to resolve symptoms for at least 12 weeks prior to surgery. Exclusion criteria were as follows: 1) traumatic spinal cord injury or fracture; 2) evident segmental instability (i.e., $>3.5 \mathrm{~mm}$ translation or $20^{\circ}$ angular motion) at the index level; 3) segmental arthrodesis without mobility; 4) severely incompetent facet joints at the index level; 5) adjacent-segment disease after previous cervical fusion; 6) ossification of the posterior longitudinal ligament; 7) ky- phosis at the index level or severe global kyphotic deformity; 8) discitis; or 9) long-term steroid use. Patients with chronic systemic diseases, including severe osteoporosis, malignancy, metabolic bone disease, autoimmune disease or spondyloarthropathy such as rheumatoid arthritis or ankylosing spondylitis, infection, or severe cerebrovascular disease such as stroke, were excluded from the current study as well.

\section{Surgical Technique}

All surgeries were performed by 3 experienced neurosurgeons and also the senior authors of the study (J.C. Wu, W.C. Huang, and H. Cheng). A consistent technique of anterior cervical discectomy was adopted, as described in previous studies..$^{5-8}$ Generous decompression of the neural element and resection of bilateral uncovertebral joints and all the bone spurs were carefully performed. The posterior longitudinal ligament was routinely removed for direct visual confirmation of decompression in the spinal canal. We always aimed for decent technique, including meticulous endplate preparation and selection of the most appropriately sized artificial disc to minimize heterotopic ossification (HO) formation..$^{33}$ Also, copious irrigation with normal saline to wash away the bone dust when drilling the osteophytes was applied in every case. After thorough decompression, a Prestige LP artificial disc was inserted in each patient in the current series. A closedsystem drainage catheter was routinely placed, followed by layer-by-layer wound closure.

\section{Measurement of Radiological Parameters and Clinical Outcomes}

Preoperative MR images, CT scans, and radiographs were reviewed for surgical indication. Our follow-up protocol involves patient-reported scores and radiographs (standing anteroposterior, lateral, and lateral dynamic flexion and extension views) at each specific follow-up time point after surgery. Patient-reported scores, including visual analog scale (VAS) of the neck and arm, Neck Disability Index (NDI) scores, and Japanese Orthopaedic Association (JOA) scores, were collected by two physician assistants under the physicians' supervision during clinic visits. The detection and grading of $\mathrm{HO}$ were established by careful review of postoperative radiographs and CT scans, and by application of McAfee's classification (Grade 0-4). ${ }^{21}$ We found that the 3D reconstructed CT scans were particularly useful for final assessment of $\mathrm{HO}$ if there was any ambiguity or discrepancy during the assessment.

Radiographic measurements included segmental ROM and overall cervical alignment. The segmental ROM of the index level was measured on standing dynamic lateral flexion/extension radiographs, obtained at 24-month follow-up examinations, using the Cobb angle method, which was the same as that previously reported on in the US FDA trials. ${ }^{24}$ The change of segmental mobility $(\Delta \mathrm{ROM})$ was defined as the differences between preoperative and postoperative segmental ROM (24-month postoperative value minus the preoperative value). Cervical alignment was assessed by using the C2-7 Cobb angle and C2-7 
sagittal vertical axis (SVA), which were measured on the standard lateral radiographs at the 24-month follow-up visit, as described previously in the literature ${ }^{30}$ (Fig. 1). Lordosis was defined as positive values of the C2-7 Cobb angle, while kyphosis was defined as negative values of the C2-7 Cobb angle. The changes in C2-7 Cobb angles and SVAs after surgery were also evaluated and yielded $\Delta C 2-7$ Cobb angle and $\Delta$ SVA, defined as the differences between pre- and postoperative values (postoperative minus preoperative Cobb angle and SVA values). The current series did not measure T-1 slope because the T-1 vertebral body was frequently obscured by soft-tissue shadow on lateral radiographs and could not be consistently evaluated. Radiological assessments and measurements were conducted by a radiologist and 2 neurosurgeons independently using picture archiving and communication system (PACS) software, SmartIris (Taiwan Electronic Data Processing Co.) on a medical-use screen in our institute.

\section{Statistical Analysis}

For analysis of continuous variables, we used t-tests,

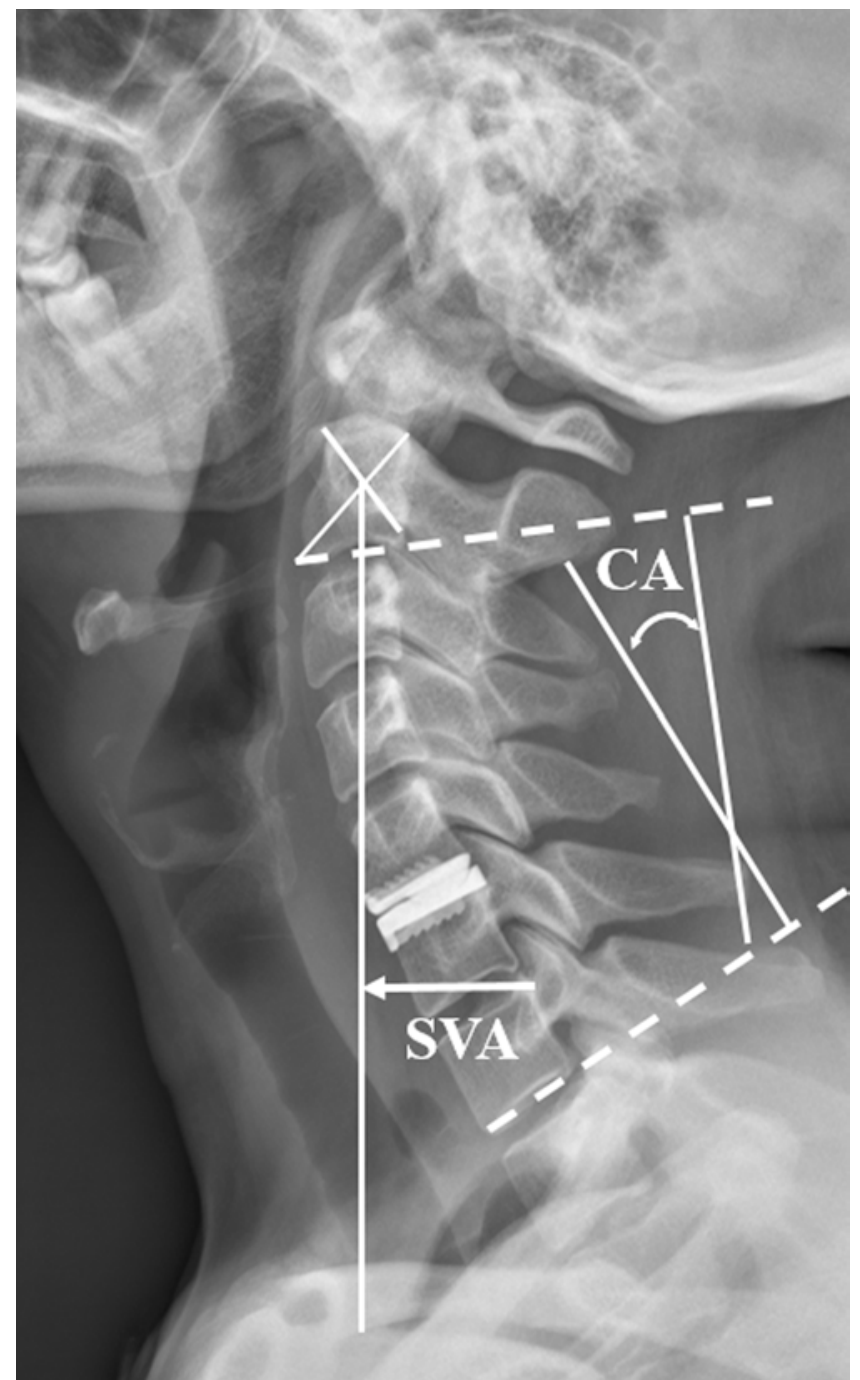

FIG. 1. Measurement of the C2-7 Cobb angle (CA) and the SVA. 1-way ANOVA tests, and correlation coefficients. Pearson's chi-square test was used for categorical variables analysis. All statistical analysis was performed using the SPSS software. Statistical significance was set at $\mathrm{p}<0.05$.

\section{Results}

\section{Demographics and Patient-Reported Clinical Outcomes}

As demonstrated in Table 1, a total of 50 patients who underwent 1-level CDA were analyzed in the current study. The Prestige LP device was implanted in all 50 patients. The mean age of the population was $45.6 \pm 9.33$ years. There was a slight female predominance (male/ female ratio 21:29). The mean follow-up period was 27.7 \pm 8.76 months. The C5-6 level was the level most commonly treated $(\mathrm{n}=36,72 \%)$. The pre- and postoperative patient-reported clinical outcomes, including neck and arm VAS, NDI, and JOA scores, are also summarized in Table 1. There was significant improvement in each of the outcome measurements at 24 months after surgery $(\mathrm{p}=$ $0.001,0.000,0.000$, and 0.000 for VAS neck, VAS arm, NDI, and JOA score, respectively).

\section{TABLE 1. Demographic data}

\begin{tabular}{|c|c|c|}
\hline Variable & Value $(\%)^{*}$ & $\mathrm{p}$ Value \\
\hline Age (yrs) & $45.6 \pm 9.33$ & \\
\hline Male/female ratio & $21: 29$ & \\
\hline Device & Prestige LP (100) & \\
\hline Follow-up (mos) & $27.7 \pm 8.76$ & \\
\hline \multicolumn{3}{|l|}{ Level } \\
\hline C3-4 & $5(10)$ & \\
\hline $\mathrm{C} 4-5$ & $7(14)$ & \\
\hline C5-6 & $36(72)$ & \\
\hline C6-7 & $2(4)$ & \\
\hline Segmental ROM $\left(^{\circ}\right)$ & & 0.596 \\
\hline Preop & $9.5 \pm 4.28$ & \\
\hline Postop 24 mos & $9.0 \pm 5.81$ & \\
\hline C2-7 Cobb angle $\left(^{\circ}\right)$ & & 0.386 \\
\hline Preop & $10.8 \pm 12.22$ & \\
\hline Postop 24 mos & $12.0 \pm 11.19$ & \\
\hline C2-7 SVA (cm) & & 0.733 \\
\hline Preop & $1.8 \pm 1.40$ & \\
\hline Postop 24 mos & $1.7 \pm 1.18$ & \\
\hline VAS neck score & & 0.001 \\
\hline Preop & $4.5 \pm 3.42$ & \\
\hline Postop 24 mos & $2.8 \pm 2.86$ & \\
\hline VAS arm score & & 0.000 \\
\hline Preop & $4.4 \pm 3.18$ & \\
\hline Postop 24 mos & $1.8 \pm 2.36$ & \\
\hline NDI score & & 0.000 \\
\hline Preop & $15.5 \pm 11.48$ & \\
\hline Postop 24 mos & $8.6 \pm 7.40$ & \\
\hline JOA score & & 0.000 \\
\hline Preop & $13.1 \pm 2.97$ & \\
\hline Postop 24 mos & $14.7 \pm 2.39$ & \\
\hline
\end{tabular}

Boldface indicates statistical significance.

* Values are presented as the number (\%) or as the mean \pm SD. 


\section{Segmental ROM and HO}

The segmental ROM at the index level was well maintained at 24 months after surgery compared with that of the same level before surgery $\left(9.0^{\circ} \pm 5.81^{\circ}\right.$ vs $9.5^{\circ} \pm 4.28^{\circ}$, $\mathrm{p}=0.596$, Table 1). The postoperative reduction in segmental mobility (ROM) was significantly correlated $(\mathrm{p}=$ 0.012) with formation of $\mathrm{HO}$ (Fig. 2). Patients in whom greater segmental ROM was achieved after CDA had a lower-grade $\mathrm{HO}$ at the index level. Once changes of ROM $(\triangle \mathrm{ROM})$ were determined postoperatively, patients were then divided into two groups accordingly: those with increased segmental mobility $\left(\Delta \mathrm{ROM}>0^{\circ}\right)$ and those with decreased or unchanged segmental mobility $(\triangle \mathrm{ROM}<$ $0^{\circ}$ ). All the clinical outcomes in the two groups were compared. The overall mean $\triangle \mathrm{ROM}$ was $-0.5^{\circ} \pm 6.13^{\circ}$ in the current series, and there were no significant differences in segmental mobility after CDA. Patients in whom segmental mobility increased $\left(\Delta \mathrm{ROM}>0^{\circ}\right)$ had significantly less $\mathrm{HO}$ and less severe HO (Figs. 3 and 4). In contrast, patients who had signs of decreased segmental mobility postoperatively (i.e., $\Delta \mathrm{ROM}<0^{\circ}$ ) had significantly higher grades of HO. ( $p=0.048$, Figs. 3 and 5). The clinical outcomes of these two groups of patients were similar during the follow-up. The changes in segmental mobility $(\Delta \mathrm{ROM})$ after CDA did not affect clinical outcomes in the current series of patients.

\section{Cervical Alignment and $\mathrm{HO}$}

The mean postoperative $\mathrm{C} 2-7$ Cobb angle did not change significantly from the mean preoperative angle $\left(12.0^{\circ} \pm 11.19^{\circ}\right.$ vs $10.8^{\circ} \pm 12.22^{\circ}$, respectively; $\left.p=0.386\right)$. The mean postoperative C2-7 SVA also did not change

\section{5}

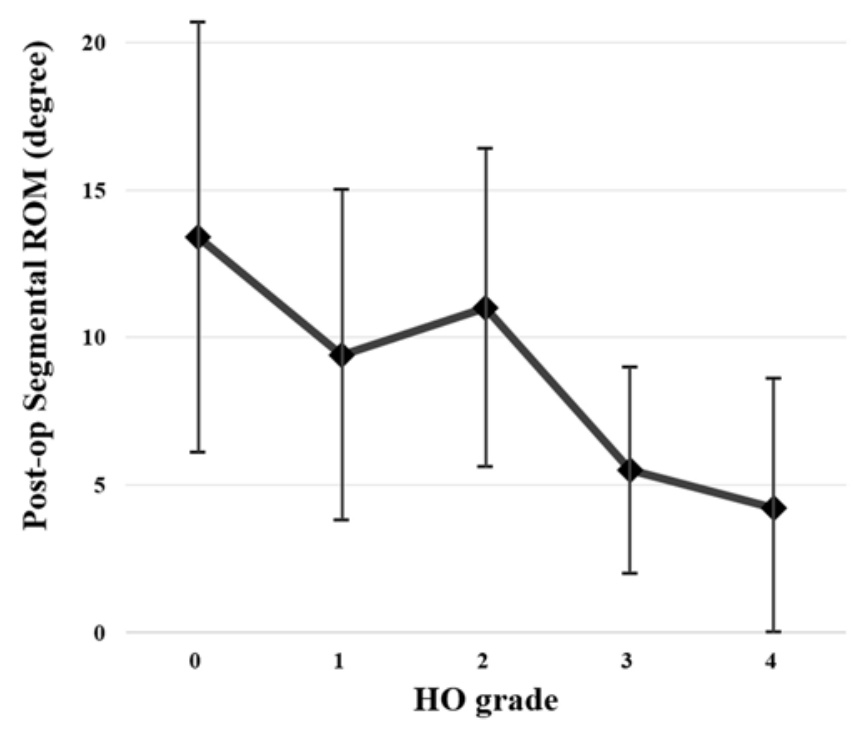

FIG. 2. The relationship between the $\mathrm{HO}$ grade and segmental mobility at the 24-month follow-up. The segmental mobility (ROM measured on lateral flexion and extension radiographs) was significantly higher in patients with lower grades of $\mathrm{HO}$ than in those with higher grades of $\mathrm{HO}$ $(p=0.012)$.

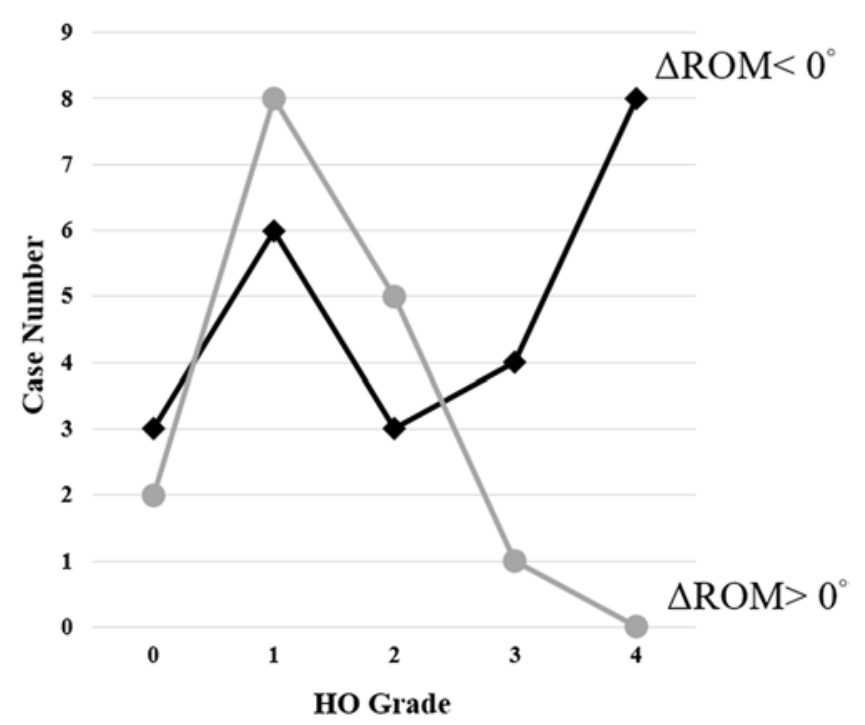

FIG. 3. Number of patients with increased segmental mobility $(\triangle R O M>$ $\left.0^{\circ}\right)$ and decreased segmental mobility $\left(\triangle \mathrm{ROM}<0^{\circ}\right)$ in each $\mathrm{HO}$ grade. Patients with increased segmental mobility $\left(\triangle \mathrm{ROM}>0^{\circ}\right)$ after $\mathrm{CDA}$ tended to have significantly less $\mathrm{HO}(p=0.048)$.

significantly $(1.7 \mathrm{~cm} \pm 1.18 \mathrm{~cm}$ [postoperative] vs $1.8 \mathrm{~cm}$ $\pm 1.40 \mathrm{~cm}$ [preoperative], $\mathrm{p}=0.733$ ). Overall cervical alignment, including both $\mathrm{C} 2-7$ Cobb angle and SVA, did not demonstrate significant changes after 1-level CDA (Table 1).

The postoperative cervical alignment, including both C2-7 Cobb angle and SVA, did not correlate with the severity of $\mathrm{HO}$ formation or the clinical outcomes (i.e., neck and arm pain VAS, NDI, and JOA scores) (Tables 2 and 3). The changes in cervical alignments, including both $\Delta \mathrm{C} 2-$ 7 Cobb angle and $\triangle$ SVA, also did not correlate with the severity of $\mathrm{HO}$ formation or the clinical outcomes. There was no statistical significance between cervical alignment parameters (C2-7 Cobb angle, C2-7 SVA, $\Delta \mathrm{C} 2-7$ Cobb angle, and $\triangle$ SVA) and degree of $\mathrm{HO}$ formation (Table 2) or between cervical alignment parameters and patient-reported outcomes (i.e., neck and arm VAS, NDI, and JOA scores [Table 3]). These alignment parameters had no association with postoperative neck pain, arm pain, neck disability, or myelopathy.

In the present series, $1(2 \%)$ of the 50 patients had intraoperative CSF leakage, which did not cause problems and required no further management. One patient $(2 \%)$ had transient C-5 palsy, which was self-limited and resolved after 3 weeks. Overall, there was no need for secondary surgery (i.e., reoperation, revision, removal of implant, or conversion of arthroplasty to fusion) and no other major surgical complications such as nerve injury, permanent dysphagia or hoarseness, wound infection, or postoperative hematoma. However, a longer time is required to follow up for complications.

\section{Discussion}

Although many FDA trials have proven the effectiveness of preserving segmental mobility after CDA at approximately $7^{\circ}-9^{\circ}$ during flexion and extension for each 

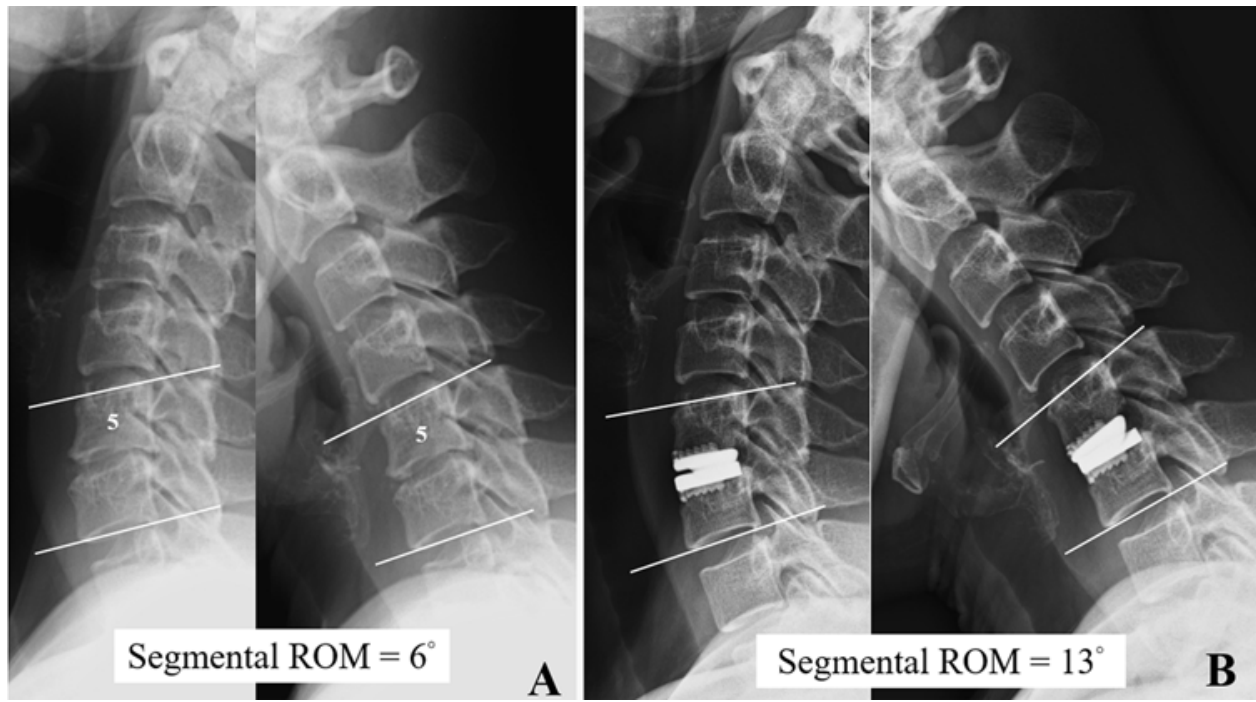

FIG. 4. Preoperative (A) (extension [left] and flexion [right]) and 24-month postoperative (B) (extension [left] and flexion [right]) dynamic lateral radiographs obtained in a female patient who underwent a C5-6 CDA. The $\triangle R O M$ was $+7^{\circ}$, and there was very little $\mathrm{HO}$ formation 2 years after CDA.

level of disc replaced, $3,17,24,25,28,34$ it is still not clear if the extent of changes in segmental mobility affects clinical outcomes. Given the fact that the postoperative ROM averaged approximately $9^{\circ}$ in the present study, there were variations among patients' segmental mobility after CDA. It is possible that CDA increased ROM in some patients while reducing ROM in others, and it might affect clinical outcomes. The present study aimed to investigate the differences between the patients whose segmental mobility was increased $\left(\Delta \mathrm{ROM}>0^{\circ}\right)$ and those whose segmental mobility decreased $\left(\triangle \mathrm{ROM}<0^{\circ}\right)$. Thus, the present series analyzed 50 consecutively treated patients who underwent 1-level CDA between C-3 and C-7. This was a single-institute experience that uniformly chose an FDA-approved device, the Prestige LP artificial disc and followed up these patients for more than 24 months. The surgical indications were 1-level symptomatic and medically intractable DDD and/or spondylosis. All imaging parameters, including segmental mobility (ROM), cervical alignment (C2-7 Cobb angle), and sagittal balance (C2-7 SVA) were assessed. Additionally, the postoperative changes in these parameters, including $\Delta \mathrm{ROM}, \Delta \mathrm{C} 2-7 \mathrm{Cobb}$ angle, and $\Delta$ C2-7 SVA, were calculated and correlated with clinical outcomes, including VAS neck pain, VAS arm pain, NDI, and JOA scores.

In the present study, 2 years after CDA, the segmental mobility was well preserved at the index level (mean $9.0^{\circ} \pm$ $\left.5.81^{\circ}\right)$, and cervical alignment exhibited little change. All
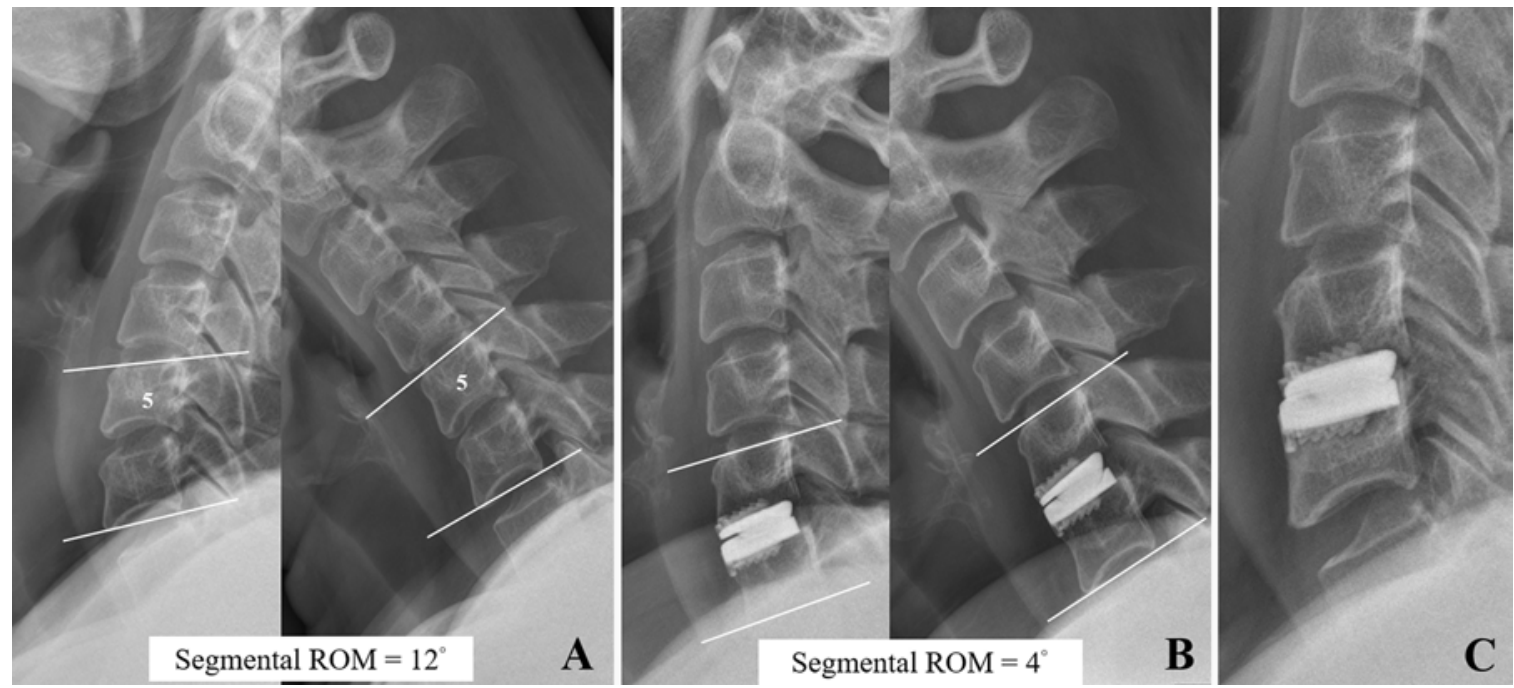

FIG. 5. A female patient who underwent a C5-6 CDA. A: Preoperative extension (left) and flexion (right) dynamic lateral radiographs demonstrated satisfactory segmental mobility. B: Three months after surgery, dynamic lateral extension (left) and flexion (right) radiographs already demonstrated decreased C5-6 segmental mobility ( $\triangle \mathrm{ROM}-8^{\circ}$ degrees). C: By 24 months after surgery, the segmental mobility was still limited and Grade $4 \mathrm{HO}$ had developed. 
TABLE 2. Relationship between $\mathrm{HO}$ grade and cervical alignment parameters

\begin{tabular}{|c|c|c|c|c|c|c|}
\hline \multirow[b]{2}{*}{ Parameter } & \multicolumn{5}{|c|}{ HO Grade } & \multirow[b]{2}{*}{$\mathrm{p}$ Value } \\
\hline & 0 & 1 & 2 & 3 & 4 & \\
\hline Postop C2-7 Cobb angle $\left(^{\circ}\right)$ & $13.9 \pm 15.94$ & $9.9 \pm 9.87$ & $8.7 \pm 10.07$ & $17.3 \pm 13.17$ & $15.1 \pm 10.27$ & 0.453 \\
\hline$\Delta \mathrm{C} 2-7 \mathrm{Cobb}$ angle $\left({ }^{\circ}\right)^{*}$ & $-2.0 \pm 10.88$ & $1.7 \pm 8.47$ & $0.9 \pm 11.47$ & $-1.0 \pm 11.51$ & $1.9 \pm 7.11$ & 0.918 \\
\hline Postop SVA (cm) & $2.4 \pm 0.40$ & $1.4 \pm 1.10$ & $1.9 \pm 1.24$ & $1.3 \pm 1.24$ & $2.2 \pm 1.40$ & 0.255 \\
\hline$\Delta S V A(\mathrm{~cm}) \dagger$ & $0.6 \pm 0.67$ & $-0.1 \pm 1.15$ & $0.2 \pm 0.64$ & $-0.1 \pm 0.89$ & $-0.3 \pm 1.61$ & 0.490 \\
\hline
\end{tabular}

patients had improved clinical outcomes, and the changes in segmental mobility $(\triangle \mathrm{ROM})$ averaged $-0.5^{\circ} \pm 6.13^{\circ}$. Those patients in whom segmental mobility increased $\left(\triangle \mathrm{ROM}>0^{\circ}\right)$ after $\mathrm{CDA}$ had similar clinical outcomes to those in whom segmental mobility decreased $(\triangle \mathrm{ROM}<$ $0^{\circ}$ ) after surgery. However, the incidence and severity of $\mathrm{HO}$ were significantly higher in patients with decreased segmental mobility $\left(\triangle \mathrm{ROM}<0^{\circ}\right)$. Moreover, segmental mobility (ROM) was significantly lower in patients with higher grades of $\mathrm{HO}(\mathrm{p}=0.012)$. This result implied that we should avoid reduction of segmental mobility during CDA surgery, because it might cause more $\mathrm{HO}$ and perhaps hinder mobility in the long term.

It was intuitive to infer that decreased segmental mobility after CDA might be associated with greater $\mathrm{HO}$ formation, and it was also reasonable to suggest that we should always aim at restoration of disc mobility when performing CDA. However, after implanting many artificial discs, we found it sometimes difficult during surgery to predict the postoperative disc mobility. Although the overall mean ROM in every series reported was similar, ${ }^{17,24,25,34}$ the actual surgical experience indicated that the disc mobility might sometimes be amplified or limited in a relatively acceptable range. The results of this present study demonstrated that mildly increased mobility, although sometimes unpredicted, might be beneficial in preserving motion after surgery because it was associated with less $\mathrm{HO}$ severity. In the literature, $\mathrm{HO}$ formation was not an uncommon phenomenon after CDA, and its incidence reportedly ranged from $12.5 \%$ to $68.2 \%$ depending on different classification and measurement tools. ${ }^{13,20,32,33}$ The risk factors for $\mathrm{HO}$ remain controversial and diverse in previously reported series and included surgical indication, operative level, male sex, hybrid constructs, surgical technique, and method of detection..$^{8,19,32,33,38-41}$ It was once reported that segmental ROM might be associated with the incidence of $\mathrm{HO}$ formation, but the study did not take
HO severity into consideration and failed to address the changes in ROM. ${ }^{27}$ The current study might add to the literature, in that decreased mobility $\left(\triangle \mathrm{ROM}<0^{\circ}\right)$ is another risk factor for $\mathrm{HO}$.

The study also demonstrated that cervical alignment did not change significantly after 1-level CDA and that the absolute values and changes in C2-7 Cobb angles and SVAs did not affect clinical outcomes. This observation perhaps corroborates the fact that patients with 1-level DDD or spondylosis should have normal cervical alignment, and if the individuals have any cervical deformity problem, they should never be considered as candidates for CDA. This paper provided evidence that there was actually little change in these alignment parameters and their effects on clinical outcomes; even some subtle mobility change existed after 1-level CDA. Based on the impact of spinopelvic alignment and sagittal balance on surgical outcome after thoracolumbar surgery documented in the past decade, ${ }^{22}$ there is also growing interest in alignment and sagittal balance of the cervical spine. Recent research has advanced our understanding of cervical alignment. For example, correction of cervical kyphotic deformity improves patients' outcomes after $\mathrm{ACDF},{ }^{30}$ and cervical sagittal malalignment is related to disability after posterior cervical fusion. ${ }^{31}$ On the other hand, few data address cervical alignment after CDA. It was reported in one study that lordotic alignment was preserved after CDA that involved implantation of the Bryan artificial disc and that this alignment was equivalent to ACDF results in an FDA trial. ${ }^{29}$ Furthermore, the Mobi-C (LDR) and Prodisc-C (DePuy Synthes Inc.) artificial discs also have been shown to preserve overall lordosis after the surgery. ${ }^{1,16}$ Only one report in the literature demonstrated that postoperative C2-7 Cobb angle had no correlation to NDI scores in patients who underwent Bryan disc-assisted arthroplasty. ${ }^{29}$ To our knowledge, this is the first study to demonstrate that the C2-7 Cobb angles, $\triangle \mathrm{C} 2-7$ Cobb angles, SVA,

TABLE 3. Correlation coefficient between clinical outcomes and cervical alignment parameters

\begin{tabular}{lrrrr}
\hline \multirow{2}{*}{ Parameter } & \multicolumn{3}{c}{ Correlation Coefficient at 24 Mos Postop $(\mathrm{p}$ value $)$} \\
\cline { 2 - 5 } & Neck VAS Score & \multicolumn{1}{c}{ Arm VAS Score } & \multicolumn{1}{c}{ NDI Score } & JOA Score \\
\hline Postop C2-7 Cobb angle $\left(^{\circ}\right)$ & $0.14(0.927)$ & $-0.01(0.997)$ & $0.145(0.325)$ & $-0.292(0.079)$ \\
\hline$\Delta$ C2-7 Cobb angle $\left(^{\circ}\right)$ & $-0.206(0.169)$ & $-0.182(0.225)$ & $-0.081(0.591)$ & $-0.078(0.611)$ \\
\hline Postop SVA $(\mathrm{cm})$ & $0.131(0.375)$ & $0.209(0.154)$ & $0.135(0.359)$ & $-0.124(0.406)$ \\
\hline$\Delta$ SVA $(\mathrm{cm})$ & $0.230(0.124)$ & $0.147(0.329)$ & $0.101(0.503)$ & $-0.066(0.668)$ \\
\hline
\end{tabular}


and $\triangle$ SVA were not statistically significant in terms of patients' outcome, including VAS, NDI, and JOA scores, after 1-level CDA.

A few studies have investigated the association between alignment and clinical outcomes after cervical fusion surgery. One prospective, randomized, double-blinded clinical study compared cervical sagittal alignment and clinical outcomes using a lordotic or parallel cage for fusion. ${ }^{36}$ The authors of that study concluded that there were no statistically significant differences in clinical outcome scores between the lordotic and parallel cage groups. Another study demonstrated that patients with cervical myelopathy treated by anterior corpectomy and fusion would develop more chronic neck pain if there was postoperative kyphosis present. ${ }^{2} \mathrm{~A}$ paper on posterior fusion surgery written on behalf of an international spine study group also demonstrated significant correlations between C2-7 SVA and SF36 scores and NDI scores, but it identified no correlations between alignment and VAS scores. ${ }^{31}$ The existing evidence on whether cervical alignment affects patient outcomes is conflicting, and there is no consensus on cutoff values for these radiological parameters suggested for patients' outcomes. Nevertheless, only selected patients (i.e., only those with disc diseases rather than facet arthropathy or deformity) among the fusion candidates should undergo CDA. For example, a patient with negative C2-7 Cobb angle should undergo ACDF even if the DDD is limited to merely 1 or 2 levels anteriorly; and since SVAs were strongly correlated with C2-7 Cobb angle, ${ }^{14}$ patients with large SVAs should also avoid CDA. The mean SVA in the present series was $1.7 \pm 1.18 \mathrm{~cm}$, whereas that reported by Tang et al. was $3.62 \pm 1.59 \mathrm{~cm} .{ }^{31}$ This indicates that the cervical alignment of arthroplasty-treated patients fell in a more narrow and specific range than in those patients who underwent fusion.

There were limitations to this study. It was a retrospective analysis of 50 patients who underwent 1-level CDA with Prestige LP disc. The 50 arthroplasty-treated levels were distributed unequally from C-3 to C-7; thus, the radiographic measurements could not represent every disc level or any other brand of CDA device. The changes in segmental mobility $(\triangle \mathrm{ROM})$, for which significance was demonstrated, might be caused by the surgical techniques applied during insertion and thus might vary in different hands. Also, the imaging parameters (ROM, C2-7 Cobb angles, and SVAs) could be subject to changes, as cervical spine degeneration continues to occur during longer follow-up periods. However, this study merits analysis of consecutive single-level arthroplasty with the same inclusion and exclusion criteria used in the FDA trials. The differences in changes in mobility separated the CDA patients by the degree of degeneration, which might yield disparities in the propensity for $\mathrm{HO}$ development. The relatively short follow-up period, averaging 27 months, was not long enough to yield differences in other clinical outcomes. Furthermore, the T-1 slope, another common radiographic parameter for evaluation of cervical alignment, was not measured in the present series because the lateral radiographs were frequently inadequate for visualization of the entire T-1 vertebra. Future investigations of a larger number of patients, longer follow-up, and optimized radiological images are required for further corroboration of the results.

\section{Conclusions}

Segmental mobility (mean ROM) and overall cervical alignment (SVA and C2-7 Cobb angle) had no significant impact on clinical outcome after 1-level CDA. Patients with increased segmental mobility $\left(\Delta \mathrm{ROM}>0^{\circ}\right)$ had significantly less $\mathrm{HO}$ and similarly improved clinical outcomes as patients with decreased segmental mobility $\left(\Delta \mathrm{ROM}<0^{\circ}\right)$.

\section{References}

1. Ahn PG, Kim KN, Moon SW, Kim KS: Changes in cervical range of motion and sagittal alignment in early and late phases after total disc replacement: radiographic follow-up exceeding 2 years. J Neurosurg Spine 11:688-695, 2009

2. Andaluz N, Zuccarello M, Kuntz C: Long-term follow-up of cervical radiographic sagittal spinal alignment after 1- and 2-level cervical corpectomy for the treatment of spondylosis of the subaxial cervical spine causing radiculomyelopathy or myelopathy: a retrospective study. J Neurosurg Spine 16:2-7, 2012

3. Burkus JK, Haid RW, Traynelis VC, Mummaneni PV: Longterm clinical and radiographic outcomes of cervical disc replacement with the Prestige disc: results from a prospective randomized controlled clinical trial. J Neurosurg Spine 13:308-318, 2010

4. Burkus JK, Traynelis VC, Haid RW Jr, Mummaneni PV: Clinical and radiographic analysis of an artificial cervical disc: 7-year follow-up from the Prestige prospective randomized controlled clinical trial: Clinical article. J Neurosurg Spine 21:516-528, 2014

5. Chang HC, Tu TH, Chang HK, Wu JC, Fay LY, Chang PY, et al: Hybrid corpectomy and disc arthroplasty for cervical spondylotic myelopathy caused by ossification of posterior longitudinal ligament and disc herniation. World Neurosurg 95:22-30, 2016

6. Chang HK, Huang WC, Wu JC, Chang PY, Tu TH, Fay LY, et al: Should cervical disc arthroplasty be done on patients with increased intramedullary signal intensity on magnetic resonance imaging? World Neurosurg 89:489-496, 2016

7. Chang HK, Huang WC, Wu JC, Tu TH, Fay LY, Chang PY, et al: Cervical arthroplasty for traumatic disc herniation: an age- and sex-matched comparison with anterior cervical discectomy and fusion. BMC Musculoskelet Disord 16:228, 2015

8. Chang PY, Chang HK, Wu JC, Huang WC, Fay LY, Tu TH, et al: Differences between C3-4 and other subaxial levels of cervical disc arthroplasty: more heterotopic ossification at the 5-year follow-up. J Neurosurg Spine 24:752-759, 2016

9. Coric D, Kim PK, Clemente JD, Boltes MO, Nussbaum M, James S: Prospective randomized study of cervical arthroplasty and anterior cervical discectomy and fusion with long-term follow-up: results in 74 patients from a single site. J Neurosurg Spine 18:36-42, 2013

10. Coric D, Nunley PD, Guyer RD, Musante D, Carmody CN, Gordon CR, et al: Prospective, randomized, multicenter study of cervical arthroplasty: 269 patients from the KineflexlC artificial disc investigational device exemption study with a minimum 2-year follow-up: clinical article. J Neurosurg Spine 15:348-358, 2011

11. Davis RJ, Kim KD, Hisey MS, Hoffman GA, Bae HW, Gaede $\mathrm{SE}$, et al: Cervical total disc replacement with the Mobi-C cervical artificial disc compared with anterior discectomy and fusion for treatment of 2-level symptomatic degenera- 
tive disc disease: a prospective, randomized, controlled multicenter clinical trial: clinical article. J Neurosurg Spine 19:532-545, 2013

12. Davis RJ, Nunley PD, Kim KD, Hisey MS, Jackson RJ, Bae HW, et al: Two-level total disc replacement with Mobi-C cervical artificial disc versus anterior discectomy and fusion: a prospective, randomized, controlled multicenter clinical trial with 4-year follow-up results. J Neurosurg Spine 22:15-25, 2015

13. Fay LY, Huang WC, Wu JC, Chang HK, Tsai TY, Ko CC, et al: Arthroplasty for cervical spondylotic myelopathy: similar results to patients with only radiculopathy at 3 years' followup. J Neurosurg Spine 21:400-410, 2014

14. Gillis CC, Kaszuba MC, Traynelis VC: Cervical radiographic parameters in 1- and 2-level anterior cervical discectomy and fusion. J Neurosurg Spine 25:421-429, 2016

15. Gornet MF, Burkus JK, Shaffrey ME, Argires PJ, Nian H, Harrell FE Jr: Cervical disc arthroplasty with PRESTIGE LP disc versus anterior cervical discectomy and fusion: a prospective, multicenter investigational device exemption study. J Neurosurg Spine 23:558-573, 2015

16. Guérin P, Obeid I, Gille O, Bourghli A, Luc S, Pointillart $\mathrm{V}$, et al: Sagittal alignment after single cervical disc arthroplasty. J Spinal Disord Tech 25:10-16, 2012

17. Heller JG, Sasso RC, Papadopoulos SM, Anderson PA, Fessler RG, Hacker RJ, et al: Comparison of BRYAN cervical disc arthroplasty with anterior cervical decompression and fusion: clinical and radiographic results of a randomized, controlled, clinical trial. Spine (Phila Pa 1976) 34:101-107, 2009

18. Janssen ME, Zigler JE, Spivak JM, Delamarter RB, Darden BV II, Kopjar B: ProDisc-C total disc replacement versus anterior cervical discectomy and fusion for single-level symptomatic cervical disc disease: seven-year follow-up of the prospective randomized U.S. Food and Drug Administration investigational device exemption study. J Bone Joint Surg Am 97:1738-1747, 2015

19. Jin YJ, Park SB, Kim MJ, Kim KJ, Kim HJ: An analysis of heterotopic ossification in cervical disc arthroplasty: a novel morphologic classification of an ossified mass. Spine $\mathbf{J}$ 13:408-420, 2013

20. Kang J, Shi C, Gu Y, Yang C, Gao R: Factors that may affect outcome in cervical artificial disc replacement: a systematic review. Eur Spine J 24:2023-2032, 2015

21. McAfee PC, Cunningham BW, Devine J, Williams E, Yu-Yahiro J: Classification of heterotopic ossification (HO) in artificial disk replacement. J Spinal Disord Tech 16:384-389, 2003

22. Mehta VA, Amin A, Omeis I, Gokaslan ZL, Gottfried ON: Implications of spinopelvic alignment for the spine surgeon. Neurosurgery 76 (Suppl 1):S42-S56, 2015

23. Mummaneni PV, Amin BY, Wu JC, Brodt ED, Dettori JR, Sasso RC: Cervical artificial disc replacement versus fusion in the cervical spine: a systematic review comparing longterm follow-up results from two FDA trials. Evid Based Spine Care J 3 (S1):59-66, 2012

24. Mummaneni PV, Burkus JK, Haid RW, Traynelis VC, Zdeblick TA: Clinical and radiographic analysis of cervical disc arthroplasty compared with allograft fusion: a randomized controlled clinical trial. J Neurosurg Spine 6:198-209, 2007

25. Murrey D, Janssen M, Delamarter R, Goldstein J, Zigler J, Tay B, et al: Results of the prospective, randomized, controlled multicenter Food and Drug Administration investigational device exemption study of the ProDisc-C total disc replacement versus anterior discectomy and fusion for the treatment of 1-level symptomatic cervical disc disease. Spine J 9:275-286, 2009

26. Phillips FM, Lee JY, Geisler FH, Cappuccino A, Chaput CD, DeVine JG, et al: A prospective, randomized, controlled clin- ical investigation comparing PCM cervical disc arthroplasty with anterior cervical discectomy and fusion. 2-year results from the US FDA IDE clinical trial. Spine (Phila Pa 1976) 38:E907-E918, 2013

27. Qi M, Chen H, Cao P, Tian Y, Yuan W: Incidence and risk factors analysis of heterotopic ossification after cervical disc replacement. Chin Med J (Engl) 127:3871-3875, 2014

28. Radcliff K, Coric D, Albert T: Five-year clinical results of cervical total disc replacement compared with anterior discectomy and fusion for treatment of 2-level symptomatic degenerative disc disease: a prospective, randomized, controlled, multicenter investigational device exemption clinical trial. J Neurosurg Spine 25:213-224, 2016

29. Sasso RC, Metcalf NH, Hipp JA, Wharton ND, Anderson PA: Sagittal alignment after Bryan cervical arthroplasty. Spine (Phila Pa 1976) 36:991-996, 2011

30. Scheer JK, Tang JA, Smith JS, Acosta FL Jr, Protopsaltis TS, Blondel B, et al: Cervical spine alignment, sagittal deformity, and clinical implications: a review. J Neurosurg Spine 19:141-159, 2013

31. Tang JA, Scheer JK, Smith JS, Deviren V, Bess S, Hart RA, et al: The impact of standing regional cervical sagittal alignment on outcomes in posterior cervical fusion surgery. Neurosurgery 76 (Suppl 1):S14-S21, 2015

32. Tu TH, Wu JC, Huang WC, Chang HK, Ko CC, Fay LY, et al: Postoperative nonsteroidal antiinflammatory drugs and the prevention of heterotopic ossification after cervical arthroplasty: analysis using CT and a minimum 2-year follow-up. J Neurosurg Spine 22:447-453, 2015

33. Tu TH, Wu JC, Huang WC, Wu CL, Ko CC, Cheng H: The effects of carpentry on heterotopic ossification and mobility in cervical arthroplasty: determination by computed tomography with a minimum 2-year follow-up: Clinical article. J Neurosurg Spine 16:601-609, 2012

34. Upadhyaya CD, Wu JC, Trost G, Haid RW, Traynelis VC, Tay B, et al: Analysis of the three United States Food and Drug Administration investigational device exemption cervical arthroplasty trials. J Neurosurg Spine 16:216-228, 2012

35. Vaccaro A, Beutler W, Peppelman W, Marzluff JM, Highsmith J, Mugglin A, et al: Clinical outcomes with selectively constrained SECURE-C cervical disc arthroplasty: two-year results from a prospective, randomized, controlled, multicenter investigational device exemption study. Spine (Phila Pa 1976) 38:2227-2239, 2013

36. Villavicencio AT, Babuska JM, Ashton A, Busch E, Roeca C, Nelson EL, et al: Prospective, randomized, double-blind clinical study evaluating the correlation of clinical outcomes and cervical sagittal alignment. Neurosurgery 68:1309-1316, 2011

37. Wu JC, Hsieh PC, Mummaneni PV, Wang MY: Spinal motion preservation surgery. BioMed Res Int 2015:372502, 2015

38. Wu JC, Huang WC, Tsai HW, Ko CC, Fay LY, Tu TH, et al: Differences between 1- and 2-level cervical arthroplasty: more heterotopic ossification in 2-level disc replacement: Clinical article. J Neurosurg Spine 16:594-600, 2012

39. Wu JC, Huang WC, Tsai TY, Fay LY, Ko CC, Tu TH, et al: Multilevel arthroplasty for cervical spondylosis: more heterotopic ossification at 3 years of follow-up. Spine (Phila Pa 1976) 37:E1251-E1259, 2012

40. Wu JC, Huang WC, Tu TH, Tsai HW, Ko CC, Wu CL, et al: Differences between soft-disc herniation and spondylosis in cervical arthroplasty: CT-documented heterotopic ossification with minimum 2 years of follow-up. J Neurosurg Spine 16:163-171, 2012

41. Yi S, Shin DA, Kim KN, Choi G, Shin HC, Kim KS, et al: The predisposing factors for the heterotopic ossification after cervical artificial disc replacement. Spine J 13:1048-1054, 2013 


\section{Disclosures}

The authors report no conflict of interest concerning the materials or methods used in this study or the findings specified in this paper.

\section{Author Contributions}

Conception and design: JC Wu, HK Chang, CC Chang, Tu, Huang, Fay, PY Chang, CL Wu. Acquisition of data: JC Wu, HK

Chang, CC Chang, Tu, Huang. Analysis and interpretation of data: JC Wu, HK Chang, CC Chang, Tu, Huang. Drafting the article: JC Wu, HK Chang, CC Chang, Tu, Huang, Fay, PY Chang, CL Wu. Critically revising the article: JC Wu, HK Chang, Huang, Cheng.
Reviewed submitted version of manuscript: JC Wu, HK Chang, Huang, Fay, PY Chang, CL Wu, Cheng. Approved the final version of the manuscript on behalf of all authors: JC Wu. Statistical analysis: HK Chang. Administrative/technical/material support: JC Wu, CC Chang, Tu, Huang, Fay, PY Chang, CL Wu, Cheng. Study supervision: JC Wu, Huang, Cheng.

\section{Correspondence}

Jau-Ching Wu, Department of Neurosurgery, Neurological Institute, Taipei Veterans General Hospital, Rm. 525, 17F, No. 201, Shih-Pai Rd., Sec. 2, Beitou District, Taipei 11217, Taiwan. email: jauching@gmail.com. 